\title{
Atividades e Formas de Comércio Urbano: novos espaços de consumo da cidade de Pau dos Ferros (RN)
}

\author{
Activities and Forms of Urban Commerce: new consumption spaces in the city of Pau \\ dos Ferros $(R N)$
}

\author{
Actividades y Formas de Comercio Urbano: nuevos espacios de consumo en la \\ ciudad de Pau dos Ferros (RN)
}

\author{
Vinícius Freitas Barros ${ }^{1}$ \\ https://orcid.org/0000-0002-3697-390X \\ Lareska Úrsula de Souza Paiva ${ }^{2}$ \\ https://orcid.org/0000-0002-2698-3557 \\ Josué Alencar Bezerra ${ }^{3}$ \\ https://orcid.org/0000-0002-7422-3018
}

\begin{abstract}
RESUMO: Os estudos sobre a urbanização e seu reflexo no espaço da cidade têm o comércio como atividade importante na análise de novas centralidades urbanas. Este estudo tem como objetivo analisar a produção dos novos espaços de comércio na última década na cidade de Pau dos Ferros, localizada no oeste do Estado do Rio Grande do Norte. Para realização desta pesquisa, buscamos o levantamento e leitura de textos associados à temática: origem e formas de comércio; a relação da globalização no espaço e na economia urbana; e sobre a produção do espaço urbano e regional. Utilizamos dados sobre os setores da economia extraídos da plataforma digital do RAIS/CAGED, identificando a presença de um processo de urbanização associado à difusão do terciário, o que projeta o comércio como atividade indutora do surgimento de novos espaços de consumo na cidade. As modificações que ocorrem no espaço se dão pela localização privilegiada e o aumento do fluxo de pessoas na cidade de Pau dos Ferros, de modo que se torna perceptível um crescimento urbano relacionado aos novos espaços de consumo e às demais formas de comércio estabelecidas na última década.
\end{abstract}

PALAVRAS CHAVE: Comércio urbano. Urbanização contemporânea. Novas centralidades. Espaços de consumo.

\footnotetext{
${ }^{1}$ Licenciatura em Geografia pela Universidade Estadual do Rio Grande do Norte (UERN-CAPF). E-mail: viniciusbarros@alu.uern.br.

${ }^{2}$ Mestranda no Programa de Pós-Graduação em Planejamento e Dinâmicas Territoriais no Semiárido PLANDITES. E-mail: lareska.geo.sousa@gmail.com.

3 Doutorado em Geografia pela Universidade Estadual do Ceará (UECE). Professor Efetivo do Departamento de Geografia/Campus de Pau dos Ferros, da Universidade do Estado do Rio Grande do Norte (UERN). E-mail: josuebezerra@uern.br.
} 


\begin{abstract}
Studies on urbanization and its impact on the city's space have commerce as an important activity in the analysis of new urban centralities. This study aims to analyze the production of new commercial spaces in the last decade in the city of Pau dos Ferros, located in the west of the state of Rio Grande do Norte. To carry out this research, we sought to survey and read texts associated with the theme: origin and forms of commerce; the relationship of globalization in space and in the urban economy; on the production of urban and regional space. We use data on economic sectors extracted from the RAIS/CAGED digital platform, identifying the presence of an urbanization process associated with the diffusion of the tertiary, which projects commerce as an activity that induces the emergence of new consumption spaces in the city. The changes that occur in the space are due to the privileged location and the increased flow of people in the city of Pau dos Ferros, so that an urban growth related to new consumption spaces and other forms of commerce established in the last decade becomes noticeable.
\end{abstract}

KEYWORDS: Urban commerce. Contemporary urbanization. New centralities. Consumer spaces.

RESUMEN: Estudios sobre urbanización y su impacto en el espacio de la ciudad sobre el comercio como actividad importante en el análisis de nuevas centralidades urbanas. Este estudio tiene como objetivo analizar la producción de nuevos espacios comerciales en la última década en la ciudad de Pau dos Ferros, ubicada en el oeste del estado de Rio Grande do Norte. Para llevar a cabo esta investigación, se buscó resaltar y leer textos asociados al tema: origen y formas de comercio; la relación de la globalización en el espacio y en la economía urbana; sobre la producción de espacio urbano y regional. Utilizamos datos de sectores económicos extraídos de la plataforma digital RAIS/CAGED, identificando la presencia de un proceso de urbanización asociado a la difusión de servicios terciarios, proyectando el comercio como una actividad que induce la aparición de nuevos espacios de consumo en la ciudad. Los cambios que se producen en el espacio se deben a la ubicación privilegiada y al aumento del flujo de personas en la ciudad de Pau dos Ferros, por lo que se advierte un crecimiento urbano relacionado con los nuevos espacios de consumo y otras formas de comercio establecidas en ese momento.

PALABRAS-CLAVE: Comercio urbano. Urbanización contemporânea. Nuevas centralidades. Espacios de consumo.

\title{
INTRODUÇÃO
}

Há tempos que os múltiplos processos de urbanização vêm sofrendo mudanças no espaço geográfico, principalmente na era da modernização da técnica e da informação, em que o comércio se tornou uma atividade importante, que vem desde a formação das cidades, e representa a dinâmica urbana deste espaço. Diante disso, o que podemos entender sobre esse processo é que a produção e organização das cidades se deu e se dá pela distribuição social e pelas atividades econômicas, seja qual for a dimensão geográfica da qual estejamos tratando (PINTAUDI, 2002).

Partindo desse pressuposto, temos a cidade de Pau dos Ferros, localizada no oeste do Rio Grande do Norte, Brasil, como nosso objeto de estudo, buscando investigar as centralidades do comércio, a partir da compreensão do reflexo da urbanização do território sob a atuação dos agentes produtores do espaço urbano (CORRÊA, 2005). Estas 
centralidades difundidas pelo comércio, a partir das novas formas de consumo e convivência, a exemplo de supermercados, lojas de conveniência, de vestuário e de utensílios variados, disputam com os espaços tradicionais (feira-livre, armarinhos e mercadinhos) simultaneamente atuando para o modelado da cidade.

Em razão desse processo, pôde-se perceber que a cidade é movida pelo capital do comércio e dos serviços, os quais se tornaram os principais instrumentos para produção desse novo espaço. Nesse sentido,

Durante muito tempo se escreveu, no caso brasileiro, ser o campo hostil ao capital, um obstáculo à sua difusão, mas o que vemos é o contrário, um campo que acolhe o capital novo e o difunde rapidamente com tudo o que ele acarreta, isto é, novas formas tecnológicas, novas formas organizacionais, novas formas ocupacionais, que aí rapidamente se instalam (SANTOS, 1994, p 142).

Nessa perspectiva, buscou-se entender como as atividades comerciais tradicionais e modernas desempenham um papel de reestruturação do espaço urbano de Pau dos Ferros, alterando, assim, a morfologia da cidade, associada à atuação dos agentes produtores do espaço (CORRÊA, 2005), a exemplo das imobiliárias, instituições financeiras, da construção civil, dos proprietários fundiários e do próprio Estado, de modo que, através do tempo, estes agentes assumem diversos papéis na expansão do espaço construído da cidade.

Para elaboração desta pesquisa qualitativa, a partir do método da dialética, se fez necessário primeiramente fazer levantamentos e leituras bibliográficas sobre o tema que destaquem os estudos do comércio urbano (PINTAUDI, 2002), o entendimento das formas do comércio (ORTIGOZA, 2009); e as dinâmicas sociais e a produção do espaço urbano que norteiam os caminhos para a compreensão de seus processos sobre o espaço urbano.

A partir disso, foi elaborado um levantamento de dados secundários a partir de bancos de informações e dados, que disponibilizam a coleta e a consulta destas para a elaboração de gráficos quantitativos e tabelas, como é o caso da plataforma RAIS/CAGED (Relatório Anual de Informações Sociais/ Cadastro Geral de Empregados e Desempregados).

O artigo está estruturado a partir desta introdução; da seção que trata do processo de centralidade urbana e comércio para produção do espaço, tomando o caso do nosso objeto empírico; a segunda acerca da relação histórica do comércio para formação territorial da cidade de Pau dos Ferros, em seguida, uma leitura sobre a configuração territorial desta cidade, observando as atividades comerciais como setor mote de análise, finalizando com as considerações finais. 


\section{CENTRALIDADE URBANA E COMÉRCIO PARA PRODUÇÃO DO ESPAÇO}

A leitura sobre o surgimento dos novos espaços de consumo passa pela necessidade de entender a organização da cidade à luz do comércio urbano. Para tanto, entende-se que a cidade é o ambiente do avanço das tecnologias e da informação, fatores esses que fortalecem o consumo de mercadorias, as quais contribuem diretamente para o crescimento econômico e, desse modo, para a intensificação da indústria.

Como assinalam Santos e Silveira (2001), o modo como as tecnologias estão ligadas ao mundo globalizado acabam interagindo simultaneamente com o comportamento humano, suas necessidades de consumo e as demais atividades que produzem o espaço.

Nesse sentido, é concebível que o comércio e as tecnologias modernas são elementos que se modificam no decorrer do tempo e, a partir dessas mudanças, nos permitem compreender melhor o espaço urbano e as suas formas, de modo que ambos se tornam indissociáveis para o surgimento de novos espaços de consumo, os quais interferem diretamente na organização e ocupação de novas áreas de uma cidade (PINTAUDI, 2002).

Desse modo, a vida na cidade capitalista está associada às atividades de consumo da população, essas ações intensificadas vêm ocorrendo cada vez mais rápido com a globalização e as formas de serviços. Para Benko (1996, p. 129):

No mundo em que vivemos, uma revolução tecnológica e uma mutação profunda das forças de produção estão transformando a vida e o trabalho humanos: elas conduziram a desenvolvimentos consideráveis das aptidões produtivas das sociedades humanas e a uma compressão espetacular do espaço e do tempo.

Compreende-se que as necessidades de consumo do homem causam grandes mudanças nos meios de produção, devido à produção em massa e à demanda de produtos, sendo eles indispensáveis para a vida, como também a variabilidade de insumos existentes para consumo no mercado.

Essa estrutura capitalista configura uma sociedade desigual e hierárquica, ocasionando fenômenos de segregação, que ocorrem involuntariamente pelas condições econômicas, a exemplo das áreas de ocupação periféricas que são dadas, ainda, como pobres e menos relevantes. Estes processos acabam sofrendo com o descaso das políticas públicas, materializando-se em bairros periféricos, favelas, comunidades de baixa renda, assentamentos ou simplesmente se tornam espaços de resistência que lutam diante das transformações organizacionais e, involuntariamente, diante das condições econômicas e sociais. $O$ que se entende dessa perspectiva é que a produção do espaço é também 
relacionada às condições de vida humana e não é produzida apenas pela função de reprodução do capital (CORRÊA, 1992).

Outro fator que também está relacionado ao crescimento das áreas urbanas é a movimentação das massas populacionais, por estas pressionarem o surgimento de novos equipamentos urbanos, a exemplo dos serviços de companhias de água e energia elétrica, hospitais para o atendimento à saúde da população, pavimentação e iluminação de áreas públicas, assim como diversas outras. Estão também relacionadas com o surgimento de novas formas de comércio e serviços especializados, de modo que a intensa variedade de seus produtos e demais mercadorias tornam-se atividades atrativas que visam estabelecer fluxos de pessoas nas demais áreas da cidade, as quais irão buscar por esses serviços oferecidos, seja pela relação de trabalho, lazer ou apenas de consumo.

O que se deve entender, nessa perspectiva, é que as relações sociais, ao longo de um processo histórico, se culminaram em buscar meios que atendessem às suas necessidades e que garantissem a sua sobrevivência pela sombra do capital. Essas ações foram responsáveis por transformar a cidade, pois, à medida que as relações sociais ocupam áreas nos espaços urbanos, elas também as transformavam, de modo que se estabelecem ainda mais, assim como o crescimento populacional nas áreas de habitação. Com essas ações, o aparecimento de diversas formas de comércio surge no espaço urbano da cidade de modo que as atividades comerciais se moldam a partir das necessidades de consumo das pessoas, alterando seu desenho em diferentes localidades, modificando a paisagem urbana. Essas transformações na morfologia da cidade, a partir do comércio, geram inúmeras aglomerações de estabelecimentos, como também dos fluxos de transportes e pessoas em busca do consumo.

Esse fenômeno passa a dar origem à concentração do capital e à formação das áreas tradicionais, as quais passam a disputar com as novas formas de consumo e as novas centralidades urbanas.

Este fenômeno pode ser visto em diversas escalas geográficas, reflexo da involução urbana verificada no Brasil a partir das últimas décadas do século passado, e que trouxe uma realidade da interiorização da rede urbana brasileira, atingindo espaços mais afastados do território (BEZERRA, 2020).

\section{A CIDADE DE PAU DOS FERROS (RN) COMO CENTRO COMERCIAL DA REGIÃO}

A atual configuração espacial de Pau dos Ferros seguiu a formação do processo de inserção desta cidade nas atividades comerciais da região, o que fomentou a sua urbanização e crescente centralização regional. O comércio que esteve presente desde sua origem foi materializado por edificações ainda presentes no território da cidade, como o 
mercado e açougue públicos e a feira-livre, e hoje com a presença de formas comerciais com lojas especializadas, franquias, supermercados e shopping center, impondo novas práticas espaciais e alterando sua paisagem urbana.

Com essas transformações, surgem as novas áreas centrais, que interagem através das relações sociais, sejam elas interurbanas ou regionais, como também com o próprio aumento da dinâmica populacional, em que as necessidades de consumo e a procura pelos demais serviços ofertados proporcionam um crescimento às demais atividades econômicas, como também da expansão e distribuição de novas formas de comércio.

Nesse sentido, busca-se explicar, neste trabalho, a importância das atividades produtivas para a expansão das dinâmicas urbanas em centros intermediários, à margem dos grandes centros urbanos brasileiros, analisando a cidade de Pau dos Ferros como objeto empírico de investigação inserida no fenômeno do comércio e consumo urbano hoje.

O município de Pau dos Ferros está localizado na região do Alto Oeste Potiguar (figura 1) e possui uma população total estimada em 30.394 mil habitantes, sendo $92 \%$ urbana (IBGE, 2019).

Figura 1 - Pau dos Ferros (RN): localização no Rio Grande do Norte, Brasil
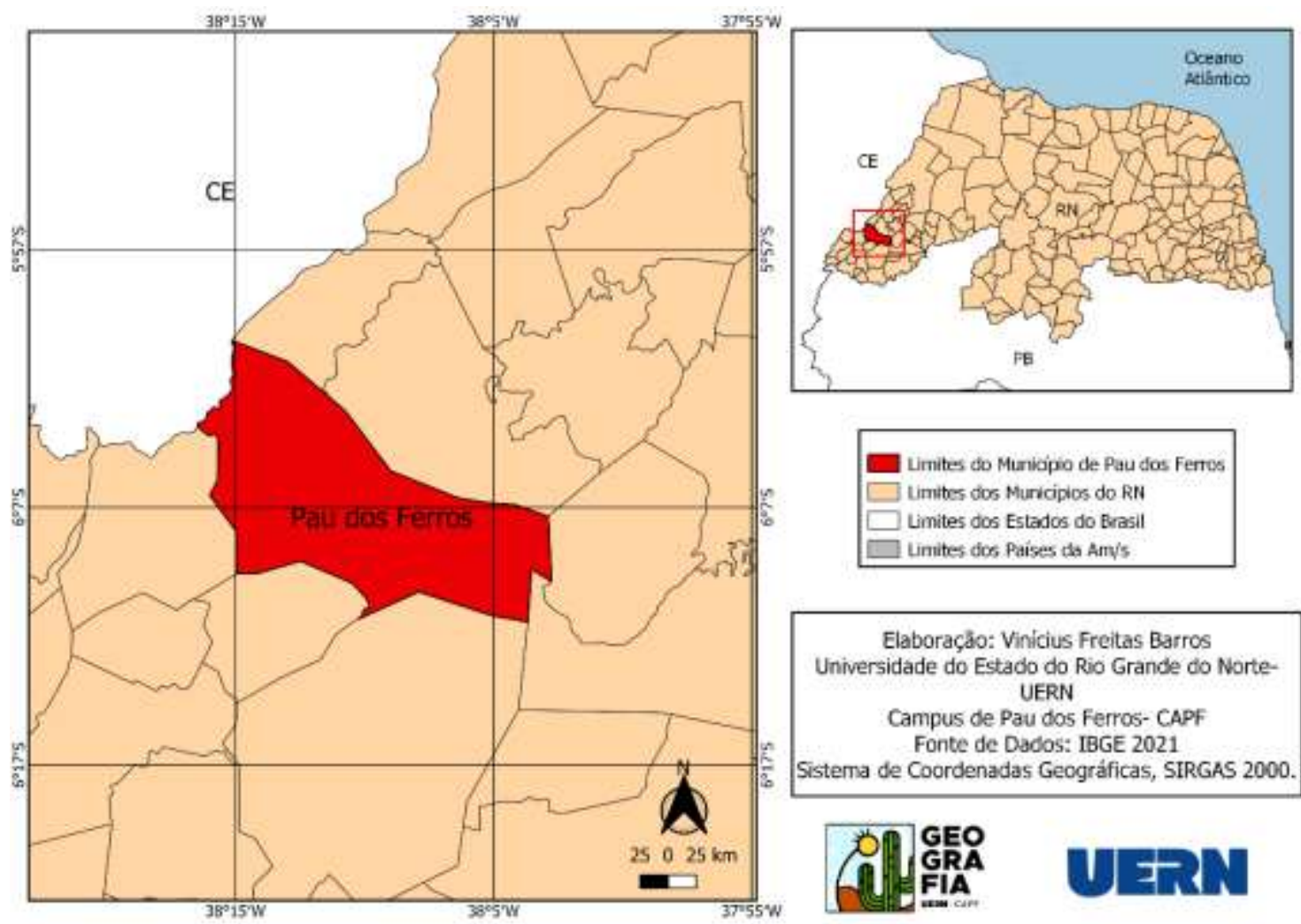

Fonte: IBGE (2019), elaboração dos autores, 2021.
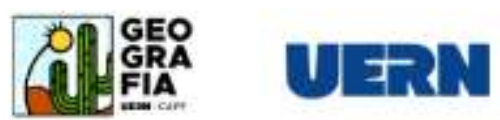

Devido à sua situação geográfica, privilegiada na região, fazendo fronteira com vários pequenos municípios do Rio Grande do Norte, Paraíba e Ceará, Pau dos Ferros torna-se 
uma cidade especial para reprodução do capital, que concentra diversas atividades de comércio e serviço na região. Pau dos Ferros acaba exercendo um papel de centralidade urbana, de modo a influenciar centros menores localizados a mais de 70 quilômetros de distância (IBGE, 2000).

A estruturação desta cidade passou por processos históricos associados à difusão de um comércio que atendeu toda uma região, o que poderá ser melhor compreendido na seção a seguir.

\section{A RELAÇÃO HISTÓRICA DO COMÉRCIO PARA FORMAÇÃO TERRITORIAL DA CIDADE PAU DOS FERROS (RN)}

A formação do território de Pau dos Ferros se inicia de modo semelhante à de outros no nordeste do século XVIII. O ciclo do gado, associado à civilização do couro, permitiu o povoamento e a expansão das regiões sertanejas (ANDRADE,1981). Neste contexto, havia a necessidade de estabelecer trilhas para a passagem do gado adentro das fronteiras territoriais, afastando os animais dos locais próximos às faixas litorâneas, onde se concentravam as atividades canavieiras.

Os caminhos do gado com destino ao sertão nordestino obtiveram relevante importância para a formação do que viriam a ser as futuras e primeiras cidades. Sendo elas, na época, caracterizadas como pequenos vilarejos que surgiam às margens das rotas, como refúgio e abrigo para os viajantes que eram encarregados da tarefa de levar os animais em suas longas e cansativas jornadas.

As rotas dos viajantes impactaram nos estudos que, posteriormente, permitiram o desenvolvimento de estradas e rodovias por toda região, em que esse fenômeno de mobilidade foi gradativamente sendo substituído pela redução das distâncias, com a abertura das estradas e formação de centros urbanos no interior do território (BARRETO, 1987).

A relação do que viria a ser uma das primeiras atividades comerciais nessas cidades, assim como em Pau dos Ferros, foi marcada por encontros de boiadeiros e viajantes, que levavam consigo diversos produtos de seus locais de origem para serem comercializados entre as proximidades das áreas de produção, e nos centros de consumo das cidades mais desenvolvidas.

Isso posto, as principais atividades que foram desenvolvidas na cidade de Pau dos Ferros foram baseadas na agricultura e na pecuária, com a comercialização da carne, do leite e do couro, assim como os próprios animais, e também com comércio de produtos regionais e oferta diversa de serviços que surgiam com o tempo. Essas atividades 
permitiram que Pau dos Ferros fosse projetada como o principal centro econômico da região. Sobre o assunto, Barreto $(1987$, p. 50$)$ relata que:

As estruturas básicas e fundamentais em que se apoia a economia do município de Pau dos Ferros encontra-se sedimentadas na pecuária, na agricultura, no comércio e num incipiente processo de industrialização que já vai adquirindo expressiva importância dentro da economia de mercados da região e do próprio município.

As atividades econômicas de $\mathrm{Pau}$ dos Ferros acompanharam 0 ritmo das transformações na dimensão do território e morfologia da cidade, que se adequaram aos crescentes números de sua população e à centralidade comercial exercida ao longo das últimas décadas.

Essa configuração tornou Pau dos Ferros um centro de influência e encontro comercial, promovendo uma interação espacial marcada por fluxos de transporte e pessoas que transitam das pequenas cidades da região para esta cidade.

\section{CONFIGURAÇÃO TERRITORIAL DA CIDADE DE PAU DOS FERROS (RN)}

Seguindo uma tendência na nova fase da urbanização brasileira (SANTOS, 1993), o terciário se tornou o setor responsável por projetar a cidade de Pau dos Ferros como uma das quatro maiores do Rio Grande do Norte (IBGE, 2020). Novas formas de comércio e serviço surgiam ao longo das últimas décadas e se intensificaram a partir dos anos 2000.

Para complementar a procura e as necessidades dos consumidores, essas ações e as mudanças nos espaços de consumo tiveram um papel importante para a intensificação da centralidade urbana de Pau dos Ferros, pois o papel comercial e de prestação de serviço e o crescimento do espaço construído que se estabeleceu em seu território nesse tempo promoveu a abertura de novas áreas na cidade, materializadas na abertura de vários loteamentos habitacionais que deram origem a novos bairros residenciais (BEZERRA, 2016).

A relação de influência existente na cidade de Pau dos Ferros para os demais municípios, como além do seus limites político-administrativos, se dá atualmente pelo seu desempenho de função ligada às atividades e equipamentos comerciais e os mais diversos serviços especializados, os quais se tornam chamariz para a procura dessas atividades na cidade, a exemplo das instituições de ensino, das lojas de roupas, móveis e eletromóveis, como também dos supermercados e os demais serviços de saúde especializados, muitos de capital externo. Temos também a utilização das formas de comércio tradicionais existentes desde a origem de Pau dos Ferros, como o mercado e o açougue públicos, a feira livre e 
outras formas de comércio e serviço coexistentes que atuam simultaneamente, principalmente na área central da cidade.

$\mathrm{O}$ atual cenário econômico da cidade de Pau dos Ferros vem se adaptando à rotina da configuração do comércio e da expansão da cidade, principalmente pela existência dos fluxos de pessoas, insumos e mercadorias, que vêm de toda região.

A distância é um elemento chave na localização e disposição dos objetos geográficos no mundo, assim como, é utilizado nas cidades, como referência no deslocamento no dia a dia das pessoas: como no trajeto do trabalho e/ou da faculdade à casa, como parâmetro na decisão de consumir um produto ou serviço não existente em uma cidade e ter que se dirigir à outra (BEZERRA, 2016, p. 286).

Diariamente, essas pessoas vêm em busca de suprir suas necessidades com os demais serviços ofertados, através dos carros de linha, que se constituem como um transporte paralelo (figura 2), que oferecem seus serviços à população regional diariamente para ir e vir de suas cidades, possibilitando se deslocar até Pau dos Ferros, promovendo uma mobilidade simples que acaba representando uma dinâmica regional neste centro que, oficialmente, tem pouco mais de 30 mil habitantes.

Figura 02 - Pau dos Ferros (RN): carros de linha que transportam a população regional para consumir na cidade
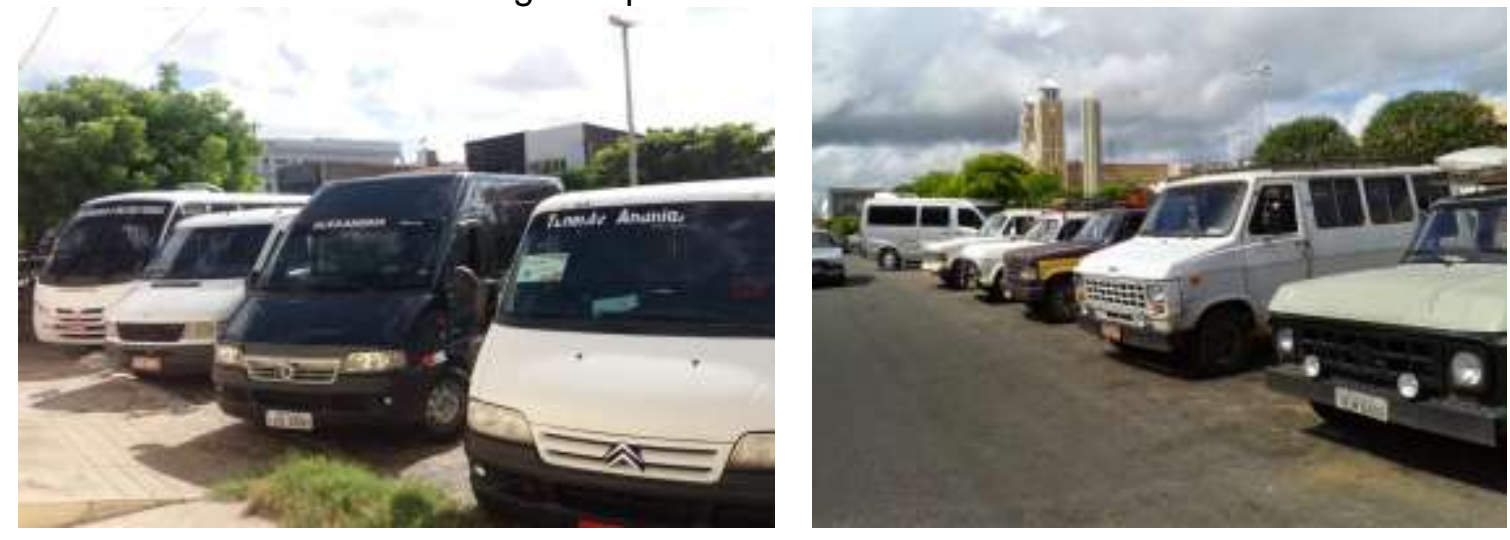

Fonte: autores, 2020.

A partir da atividade de transporte por carros de linha, percebemos a dimensão dos equipamentos voltados para o comércio e dos demais serviços especializados sediados em Pau dos Ferros, os quais estão preparados para receber uma população regional, com supermercados amplos e modernos, clínicas de exames médicos com procedimentos mais complexos, lojas de roupas e calçados voltadas para várias camadas de renda, de modo que se estabeleceram em diversos pontos localizados na cidade.

A configuração das atividades econômicas desse setor tornou-se uns dos fatores responsáveis para a dinâmica de crescimento urbano de Pau dos Ferros, impulsionando o 
mercado imobiliário e possibilitando a origem de novas formas de consumo em outras áreas da cidade. Nesse sentido, é preciso entender que:

Dentro dessa dinâmica, para compreender a materialização das formas comerciais no espaço urbano temos que, necessariamente, analisá-las dentro do processo de reprodução como um todo. Em outras palavras, é só através da análise da essência dos processos que notamos que a reprodução não é o novo totalmente, ela o contém mantendo algo do velho. No caso das formas comerciais, pode-se dizer que sua essência é dada pelo uso que é a mediação entre tempo e espaço. Nesse caso, não são as novas formas comerciais que transformam a vida; é o uso que, dado pela vida cotidiana, dá o novo sentido à forma, muitas vezes transformando-a (ORTIGOZA, 2001, p. 3-4).

A representatividade do comércio configura diretamente na organização e produção dos novos espaços de consumo e na formação de subcentros (PINTAUDI, 2002), dessa maneira, podemos considerar que essas ações podem ser visualidades em Pau dos Ferros na formação de novas centralidades urbanas. Sobre esse fenômeno, Salgueiro (2006, p. 15) coloca que:

\begin{abstract}
Estas novas centralidades são espaços de grande valor pela sua localização, pela quantidade e pelo prestígio do sítio e dos edifícios; são os sítios mais adequados para os negócios, que oferecem maior qualidade de vida às famílias, que propiciam maiores economias. Fonte apetecível de acumulação de capital, atraem investimentos e empresas. Numa sociedade intensiva em informação e conhecimento, as TIC, as conexões rápidas e outros sistemas de infraestruturas, são cruciais na valorização, pelo que estes projetos são, no geral, mais bem servidos do que o resto da cidade.
\end{abstract}

Outro exemplo do que já foi mencionado a respeito dos fluxos é que muitos deles passam a ser fixos justamente pela interação de consumo e necessidades das pessoas, pois os lugares passam a ser um produto das práticas sociais individuais e coletivas para reprodução e de identificação (SALGUEIRO, 1996). Nesse caso, o aumento da população local, junto às atividades econômicas, passa a ser agente responsável pelo crescimento urbano e para o surgimento dessas centralidades na cidade.

Alguns pontos estratégicos das áreas de consumo de Pau dos Ferros são os tradicionais, como os espaços de resistência (figuras 3 e 4), tendo como exemplo a feira livre da cidade, como uma das atividades econômicas marcante desde a sua formação. A feira tem um papel importante para diversos comerciantes varejistas da região, como também é dotada de tradição para diversos moradores da cidade, ela funciona em quase todos os dias da semana e tem seu maior pico de extensão e movimentação aos sábados, de modo que se torna ponto de encontro de vendedores, consumidores e demais pessoas 
que buscam lazer e mercadorias e variedades que não encontram em seus municípios. No caso dos residentes de Pau dos Ferros, sua busca é pelos baixos preços dos produtos.

Figura 03 - Pau dos Ferros (RN): bancas da feira livre

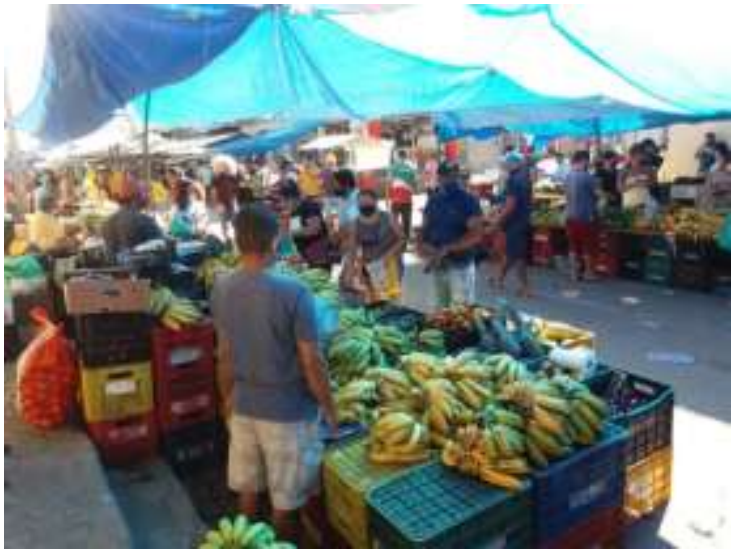

Fonte: autores, 2020.
Figura 04 - Pau dos Ferros (RN): comércio de produtos sertanejos

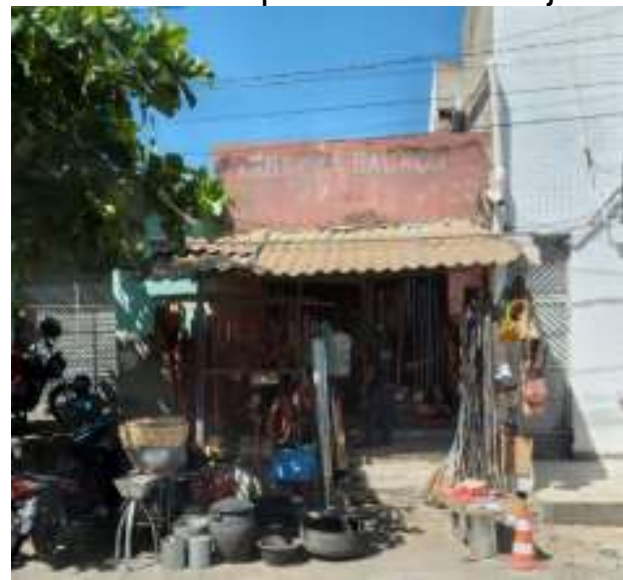

Fonte: autores, 2021.

A movimentação dos constantes fluxos de pessoas que passam pela feira torna-se alvo de outras atividades comerciais e serviços especializados, que se estabelecem próximo onde se localiza a feira livre. Desse modo, é compreensível que ela representa um ponto primordial de organização, fluxos e mudanças nas formas de comércio existentes à sua volta. Mesmo com tantas atividades modernas, é perceptível que, em plena globalização: [...] a feira se destaca no contexto do lugar como lócus de resistência onde estão envolvidos o pequeno agricultor que negocia sua própria produção, os artesãos com seus produtos regionais, os violeiros, os repentistas e os inúmeros curiosos (VIEIRA, 2004, p. 1).

Em diversas cidades do Nordeste a feira livre possui uma função cultural básica de concentrar diversos produtos regionais, principalmente os relacionados à agricultura e à pecuária, de modo a tornar-se palco para troca e compra entre diversos vendedores, comerciantes e consumidores. A feira atua também como um lugar de tradição, onde ocorrem encontro e reencontros de pessoas e de múltiplos eventos, alterando momentaneamente a dinâmica da cidade nos dias de sua ocorrência.

Segundo Araújo (2012), a feira é esse local de sociabilidade, muitas pessoas se deslocam semanalmente para os centros urbanos, pessoas essas que são oriundas da zona rural. Nesse sentido, a feira se torna caracterizada por múltiplos sujeitos, modificando aquele local, mesmo ocorrendo em período curto.

Um outro importante ponto comercial e cultural de Pau dos Ferros é o açougue público, localizado próximo à feira livre, local de tradição para o município, pois esta é uma das primeiras formas que foram geridas na cidade. No ano de 2019 o açougue público foi reformado e passou por mudanças organizacionais, com novas instalações e modernização 
da sua infraestrutura; hoje, o açougue encontra-se dividido por boxes mais higiênicos e uma melhor distribuição dos espaços, facilitando para que os açougueiros e os clientes se movimentem e se orientem dentro do local.

Por mais que esses pontos comerciais permaneçam até hoje exercendo suas funções no município, não são mais as principais para o setor econômico, no entanto suas atividades históricas foram essenciais para o desenvolvimento e modernização dos demais equipamentos na cidade e, principalmente com a concorrência dos novos estabelecimentos e espaços de consumo, esses locais tradicionais se consolidaram em Pau dos Ferros, porém buscam se adequar às mudanças que ocorrem no tempo.

Além desses espaços de consumo supracitados, existe também o mercado público, sendo este um dos pontos mais antigos da cidade, e este sempre funcionou como estabelecimento para inúmeras atividades comerciais e, assim como o açougue, também sofreu alterações nos últimos anos e recebeu novas instalações, de modo que esteticamente mudou grande parte de sua morfologia, preservando poucos aspectos da sua antiga estrutura. Sua localização é no centro da cidade, mais precisamente em frente à Praça Monsenhor Caminha, também conhecida por Praça da Matriz pelos habitantes, por estar nos arredores da igreja da cidade.

Essas atividades comerciais estão sempre em mudança, como também os seus locais de centralidade, os quais se estruturam e se reestruturam formando novos espaços de consumo (PINTAUDI, 2002).

A cidade de Pau dos Ferros possui o tradicional materializado na feira livre e no mercado público, e os que são voltados aos novos padrões de consumo, nas formas comerciais dos supermercados de capital externo (figuras 5 e 6).

Figura 5 - Pau dos Ferros (RN): loja do Nosso Atacarejo, pertencente ao grupo empresarial do Ceará

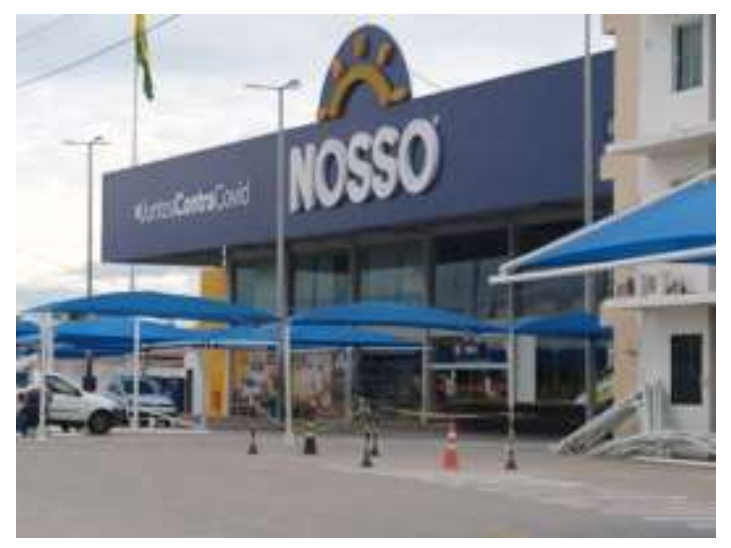

Fonte: autores, 2021.
Figura 6 - Pau dos Ferros (RN): loja do supermercado Nonato, originado de Mossoró (RN)

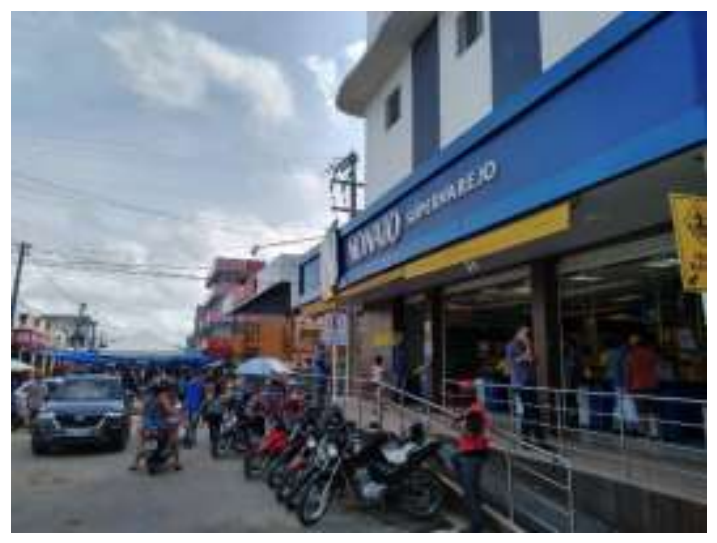

Fonte: autores, 2021. 
Estes equipamentos representam uma contribuição para um processo de urbanização gerido a partir da difusão e distribuição de novas formas de comércio da cidade. Os espaços modernos citados acima deram outra dinâmica à cidade, aumentando os fluxos de transportes e pessoas em suas centralidades. Os estabelecimentos atuam como agentes que produzem e transformam o espaço, devido à grandeza e à configuração que exercem. $A$ partir de suas existências, outras atividades econômicas e serviços se mobilizam para complementar a relação de procura e necessidade dos consumidores, se instalando próximo à suas localidades, a exemplo dos pontos de mototáxis, os estabelecimentos que oferecem serviço de crédito para celulares, os bares, as lanchonetes, as padarias e os restaurantes, entre diversos outros pequenos pontos comerciais e prestadores de serviço que se estendem ao longo do raio de influência dessas formas modernas.

O Plaza Shopping Center, inaugurado em 2018 (figura 7), está localizado próximo à praça da matriz, e conta com lojas que ofertam serviços de lazer e produtos diversos, assim como uma praça de alimentação com restaurantes, entre outras atividades. Possui também uma estrutura e um ambiente diferente e moderno para os padrões da cidade, pois, até então, não havia nada parecido.

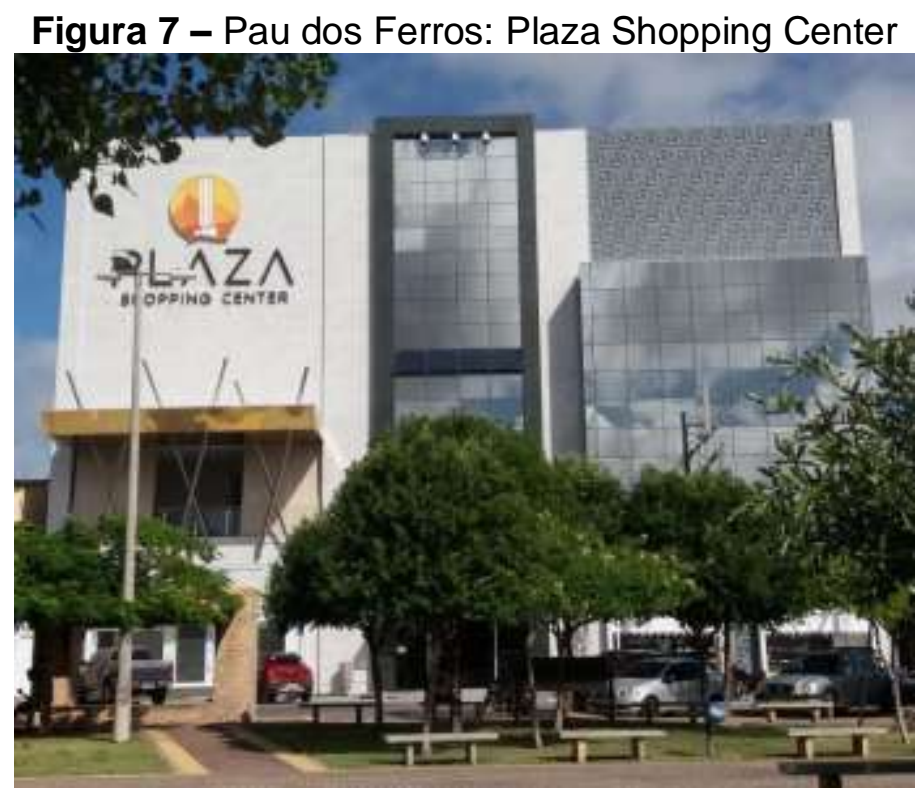

Fonte: autores, 2020.

Sua configuração no espaço tornou a localidade ainda mais movimentada, permitindo mudanças na dinâmica da cidade de Pau dos Ferros, e pôde-se perceber o surgimento de uma nova centralidade, a partir das mudanças que ocorrem na organização do espaço local, originando uma nova característica que se torna referência para o uso das técnicas de venda de produtos e de serviços ofertados, assim como a valorização das demais áreas e estabelecimentos próximos (PINTAUDI, 2002). 
A relação do shopping também se deu pela adequação dos valores para o seu público alvo, sendo esses pertencentes a um público mais jovem, que buscou atender com mais variedade e uso das franquias e marcas famosas reconhecidas, estratégia essa como forma de padronizar uma elite consumidora naquele local e se tornar exclusivamente detentora desses serviços na cidade.

As mudanças na dinâmica urbana de Pau dos Ferros vêm refletindo o surgimento de comércios mais estruturados e de serviços especializados que tornam o terciário moderno um fator importante para seu crescimento, de modo que essas ações vêm acontecendo simultaneamente através das múltiplas formas que alteram o espaço urbano, permitindo, neste caso, que Pau dos Ferros desenvolva um papel de centro para a região, através da procura dos estabelecimentos de comércio e serviço ofertados na cidade. Um exemplo disso é a construção de grandes estabelecimentos que oferecem novos formatos de compras de atacado para a comunidade (figura 8).

Figura 8 - Pau dos Ferros (RN): construção de novo supermercado da rede SuperQue

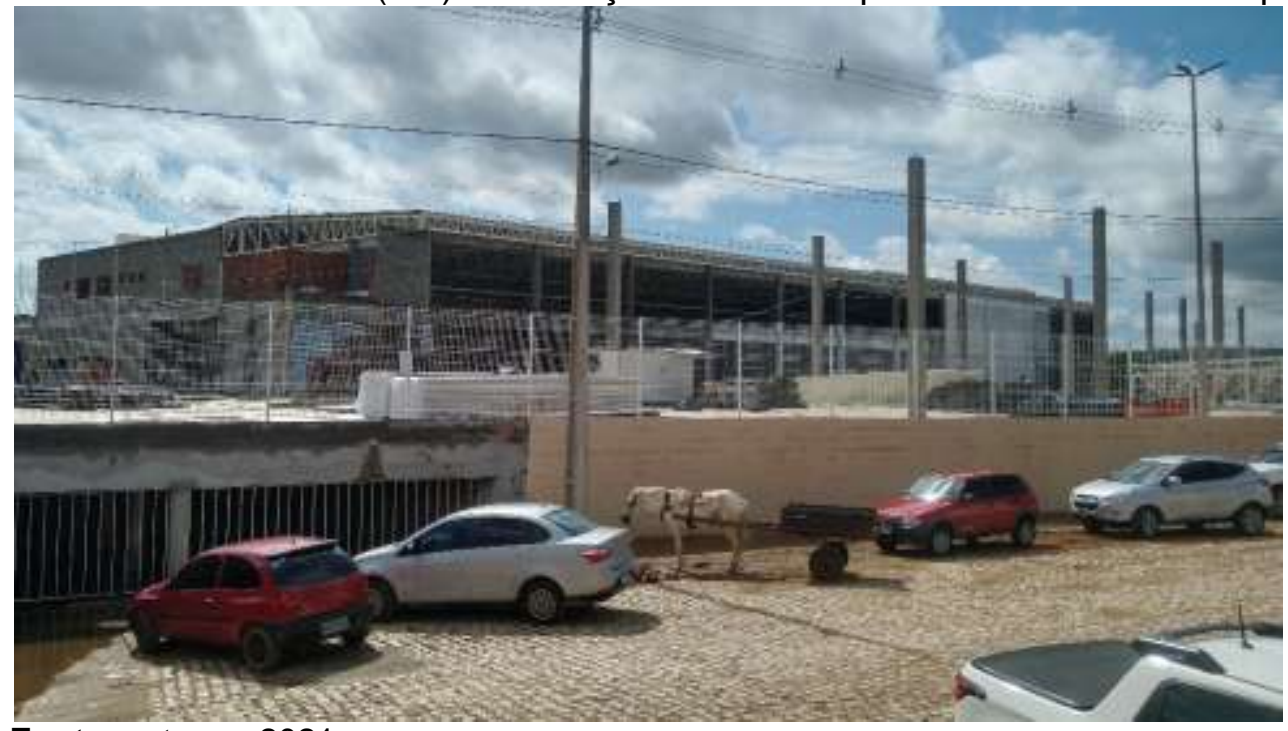

Fonte: autores, 2021.

A partir de sua instalação na cidade é que fluxos interurbanos passaram a ser maiores, e as dinâmicas de sua configuração, assim como a do shopping, valorizam as áreas da proximidade, a exemplo das residências e demais imóveis que já existiam, como postos de combustível, oficinas de venda e consertos de automóveis, bares, padarias e lojas de materiais de construção, entre outros.

Além dos estabelecimentos já existentes, surgiram outras atividades nas proximidades, a exemplo da presença dos carros de linha e mototáxis. Os estabelecimentos que seguem o formato de venda no varejo e no atacado estabeleceram um novo espaço e forma de consumo que visa redistribuir uma parcela da população consumidora, sendo 
esses os que optam por fazer suas compras em seu estabelecimento, atraídos por meio de uma estratégia de venda, no qual são oferecidas inúmeras variedades de produtos e um espaço com conforto, a exemplo de uma música de fundo e ambiente climatizado, como também de um preço por atacado que facilite o interesse de aquisição de seus consumidores.

Apesar dos espaços modernos oferecerem novas formas de compra e variedades de produtos, assim como diferentes possibilidades de pagamento para seus clientes, há aqueles que se prendem às tradições e às condições de identidade com o lugar, preferindo ainda comprar nesses estabelecimentos menores e tradicionais, sendo este um exemplo de espaço de resistência, que acabam disputando com as grandes formas de comércio. Essas interações acontecem simultaneamente e são mais comuns entre o moderno e o tradicional.

Essa relação de disputa das formas de comércio e serviço na cidade de Pau dos Ferros e a combinação das ações sociais para promover o crescimento de novas áreas da cidade acabam se tornando cada vez mais evidente à maneira que esse processo vem se desenvolvendo a partir dessas atividades econômicas.

A partir de dados extraídos da plataforma do RAIS/CAGED (2020), é possível reforçar as informações que foram apresentadas nessa pesquisa. A plataforma em questão traz informações socioeconômicas de trabalho e emprego, assim como dados de empregadores e pessoas jurídicas entre diversas outras informações do setor produtivo em diversas escalas do território. Dessa forma, foi necessário coletar os dados dos principais setores econômicos da cidade, voltados à indústria, comércio, serviço, agropecuária e construção civil (figura 9).

Figura 9 - Pau dos Ferros (RN): percentual de estabelecimentos por setor de atividade (2019)

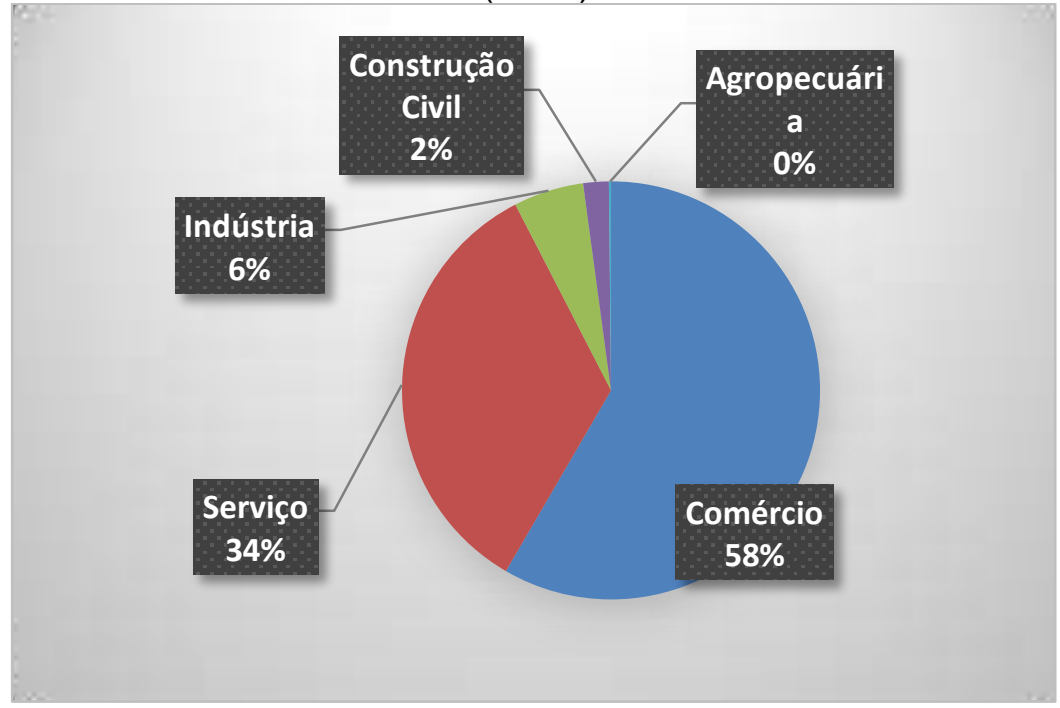

Fonte: RAIS/CAGED, 2020. 
Podemos observar a predominância do comércio e do serviço em Pau dos Ferros e como as outras atividades econômicas incluem apenas uma pequena fração desse todo. Nele, é possível ter uma interpretação de como funciona o setor econômico da cidade, representado pela predominância do setor terciário.

Estes dados representam um reflexo do que ocorria na urbanização brasileira no final do século $\mathrm{XX}$, com reestruturação produtiva direcionada para uma interiorização da rede urbana no território (BEZERRA, 2020). Desse modo, percebemos uma redistribuição pelo território no início do século XXI, com a modernização dos equipamentos e nas políticas de Estado, promovendo a indústria e as demais atividades comerciais para inserção no solo urbano das pequenas e médias cidades, provocando o deslocamento da população rural para as áreas urbanas (SANTOS, 1993).

Esse processo contribuiu para o fortalecimento e o surgimento de inúmeros municípios. No Nordeste brasileiro, esse fenômeno foi ainda mais intenso e permitiu que cidades como Pau dos Ferros surgissem, estabelecendo atividades econômicas voltadas ao terciário, promovendo o comércio e o serviço como predominantes para sua formação.

Estas atividades econômicas influenciam as dinâmicas organizacionais da cidade, partindo do surgimento dos novos estabelecimentos, da hegemonia das grandes empresas e dos novos consumidores.

A ideia de apresentar esse recorte temporal nos ajuda a entender os resultados que indicam o crescimento urbano de Pau dos Ferros, a partir do comércio e do serviço, e, assim, a importância do terciário para a cidade, como também as mudanças nas atividades econômicas e no surgimento de espaços de consumo e, consequentemente, de novas centralidades, sendo essas ações fundamentais para o crescimento populacional, como também para a distribuição geográfica ocupacional dessa população, tornando, assim, esta cidade cada vez mais importante para região do Alto Oeste Potiguar.

\section{CONSIDERAÇÕES FINAIS}

A pesquisa buscou apresentar os resultados das relações sociais com as formas de comércio, sendo esse um fator que possibilita o surgimento de novas áreas de consumo, de modo que contribuem para a expansão das áreas urbanas do município. Essa circunstância reflete para a cidade um impulso para o acréscimo de seus fluxos urbanos e regionais, através da procura das pessoas pelos serviços e demais atividades comerciais exercidas em Pau dos Ferros.

É, nessa perspectiva, que podemos identificar um quantitativo significativo e diversificado do comércio na cidade, sendo uma cidade de caráter regional que, de acordo 
com Bezerra (2016), apresentam uma diversidade no setor comercial e também nos serviços especializados, em que o comércio se apresenta como um elemento importante na cidade, atraindo pessoas das cidades vizinhas.

Com os demais fluxos e o crescimento das áreas comerciais na cidade, Pau dos Ferros obteve um aumento no fluxo população regional como visto por Bezerra (2016), processo este que sugere uma distribuição residencial próxima ao centro, e das localidades que oferecem tipos de serviço especializado, de modo que, consequentemente, resultou no crescimento de várias áreas urbanas na cidade.

Esse processo de produção do espaço por meio da expansão das formas e crescimento da população impactou na morfologia da cidade, sendo diretamente associada às dinâmicas da cidade, estruturando o espaço interurbano, dando forma e modelando. Nesse sentido, deve-se considerar também a modernização de suas formas através dos novos equipamentos urbanos, os quais surgem por meio da necessidade de atender à demanda da sociedade.

Considerando a análise do reflexo do fenômeno comercial urbano de Pau dos Ferros, pode-se concluir que a cidade assumiu um papel regional importante, adotando uma influência para os demais municípios do Alto Oeste Potiguar.

Nesse sentido, por mais que o comércio atue como uma atividade que fortalece a produção do espaço e dinamiza o interurbano, há necessidade de observar as áreas de interesse do capital comercial, à luz da urbanização contemporânea.

Vale ressaltar que esse processo não acontece simultaneamente em todas as localidades da cidade, e que se apropria dos espaços, por meio dos agentes produtores e consumidores do espaço e seus respectivos fragmentos, sendo reflexo das condicionantes sociais e da materialização de suas formas espaciais (CORRÊA, 2005), representado pela valorização e interesses do capital, ligados ao reflexo da modernização, de modo que possibilita o surgimento de novas centralidades e espaços de consumo em diferentes localidades do solo urbano da cidade.

Esta relação do crescimento e modernização urbana acontece de forma desigual entre os espaços, assim como suas atuais formas, algumas áreas consideradas elitizadas pelas classes sociais obtém um avanço maior e mais significativo do que em áreas consideradas periféricas.

No caso de Pau dos Ferros, isso se dá pelo fato que as formas de comércio e os tipos de serviço especializados se estabelecem ao longo da cidade, visando o fluxo de capital e mercadorias, assim como os novos tipos de consumidores, proporcionando à cidade um crescimento a partir da ocupação de suas áreas de aproximação ao centro comercial, estabelecendo à cidade um crescimento de forma horizontal, um crescimento sem 
planejamento e não controlado, sendo essa uma característica que não acompanha os outros espaços já urbanizados da cidade.

A pesquisa confirma que cidades interiorizadas, como Pau dos Ferros, que crescem de maneira desordenada, tornam-se espaços dispersos no território, o que caracteriza um novo aspecto da rede urbana brasileira.

\section{REFERÊNCIAS}

ANDRADE, Manoel Correia de. A produção do espaço norte-rio-grandense. Natal: Universitária UFRN, 1981.

ARAUJO, Giovanna. Aspectos sociais do cotidiano das feiras livres: um estudo etnográfico em território português e em solo brasileiro. Maringá Management: Revista de Ciências Empresariais, v. 9, n.2, - p. 49-64, jul./dez. 2012.

BARRETO, José Jácome. Pau dos Ferros: história, tradição e realidade. Natal: Carlos Lima, 1987.

BENKO, Georges. Economia, espaço e globalização na aurora do século XXI. São Paulo: Hucitec, 1996.

BEZERRA, Josué Alencar. A cidade e região de Pau dos Ferros: por uma geografia da distância em uma rede urbana interiorizada. Tese (Doutorado em Geografia). Universidade Estadual do Ceará, Centro de Ciências e Tecnologia, Programa de Pós-Graduação em Geografia, Fortaleza, 2016.

BEZERRA, Josué Alencar. Rede urbana interiorizada: novas conformações do território no Nordeste Brasileiro. Sociedade \& Natureza, v. 32, p. 392-403, jun. 2020.

CORRÊA, Roberto. Lobato. Corporação, Práticas Espaciais e Gestão do Território. Revista Brasileira de Geografia, Rio de Janeiro, v. 54, n. 3, p. 115-122, jul/set, 1992.

CORRÊA, Roberto. Lobato. Espaço, um conceito-chave da Geografia. In: CASTRO, Iná Elias de; GOMES, Paulo César da Costa; CORRÊA, Roberto Lobato (Orgs.). Geografia: conceitos e temas. Rio de Janeiro: Bertrand Brasil, 2005. p. 15 - 47.

IBGE (INSTITUTO BRASILEIRO DE GEOGRAFIA E ESTATÍSTICA). Região de Influência das Cidades: Coordenação de Geografia. Rio de Janeiro: IBGE, 2000.

IBGE (INSTITUTO BRASILEIRO DE GEOGRAFIA E ESTATístICA). Pau dos Ferros. Disponível em: https://www.ibge.gov.br/cidades-e-estados/rn/pau-dos-ferros.html. Acesso em: 22 abr. 2019.

IBGE (INSTITUTO BRASILEIRO DE GEOGRAFIA E ESTATÍSTICA). Estatísticas populacionais de Pau dos Ferros RN. Disponível em: <https://cidades.ibge.gov.br/brasil/rn/pau-dos-ferros>. Acesso em: 22 abr. 2020.

ORTIGOZA, Silvia Aparecida Guarnieri. O tempo e o espaço da alimentação no centro da metrópole paulista. 2001. Tese (Doutorado em Geografia) - Instituto de Geociências e Ciências Exatas, Universidade Estadual Paulista, Rio Claro, 2001.

ORTIGOZA, Silvia Aparecida Guarnieri. Geografia e consumo: dinâmicas sociais e a produção do espaço urbano. Tese (Livre-docência em Geografia). UNESP, Rio Claro, 2009.

PINTAUDI, Silvana Maria. A cidade e as formas do comércio. In: CARLOS, Ana F. A. (Org.). Novos caminhos da Geografia. São Paulo: Contexto, 2002. p. 143-158. 
RAIS - Manual de Orientação da Relação Anual de Informações Sociais (RAIS), objeto de estudo: Pau dos Ferros. Disponível em: http://bi.mte.gov.br/bgcaged/. Acesso em: 21 abr. 2020.

SALGUEIRO, Teresa Barata. Do comércio à distribuição: roteiro de uma mudança. Oeiras, PT: Celta, 1996.

SALGUEIRO, Teresa Barata. Oportunidades e transformação na cidade centro. Finisterra, XLI, 81, p. 9-32, 2006. p. 9-32.

SANTOS, Milton. A urbanização brasileira. São Paulo: Edusp, 1993.

SANTOS, Milton. Técnica, espaço, tempo: globalização e meio técnico-científico informacional. São Paulo: Hucitec, 1994.

SANTOS, Milton; SILVEIRA, Maria Laura. O Brasil: território e sociedade no início do século XXI. Rio de Janeiro: Record, 2001.

VIEIRA, Rute. Dinâmicas da feira livre do município de Taperoá/PB. Paraíba, DEGEOC/UFPB, 2004. Disponível em: <http://www.cibergeo.org/agbnacional/VICBG2004/Eixo1/e1_024.htm>. Acesso em: 15 set. 2004.

Recebido: agosto de 2021. Aceito: novembro de 2021. 